\title{
EL USO DEL RELATO AUTOBIOGRÁFICO COMO ELEMENTO DE EVALUACIÓN: UNA EXPERIENCIA EN EDUCACIÓN SUPERIOR
}

The use of the autobiographical tale as an assessment element: an experience in higher education

O uso de relato autobiográfico como um elemento de avaliação: uma experiência no ensino superior

Jorge Lizandra (1)

Javier Monforte (2)

\section{Alexandra Valencia-Peris (3)}

(1) Universitat de València, España. Teléfono: +34 961625094. Correo electrónico: jorge.lizandra@uv.es

(2) Universitat de València, España. Teléfono: +34 963983309. Correo electrónico: javier.monforte@uv.es

(3) Universitat de València, España. Teléfono: +34 963828920. Correo electrónico: alexandra.valencia@uv.es

\section{Resumen}

En este trabajo se hace uso del relato autobiográfico como elemento de evaluación. Se solicitó al estudiantado que redactara dos relatos, uno con los recuerdos de las clases de educación física (EF) antes de haber cursado sus estudios de magisterio y otro en el que ofrecieran su visión de la EF después de haber cursado la asignatura de didáctica de la EF en educación primaria (EP). En el primer relato, destacaron los recuerdos negativos, en muchos casos debido a un enfoque tradicional de la asignatura basado en la ideología del rendimiento. En cambio, tras haber ofrecido un enfoque alternativo en la asignatura del grado en el cual se justifica el valor educativo de la EF, se observó en los relatos un cambio muy positivo sobre el significado y la justificación de la inclusión de esta asignatura en el currículum de EP.

Palabras claves: Evaluación; relato autobiográfico; educación física; educación superior 


\begin{abstract}
In this work the autobiographical story is used as an evaluation element. The students were asked to write two stories, one with the memories of the physical education (PE) classes before they had completed their teaching studies and another in which they offered their view of PE after they had taken the subject of didactics of PE in primary education. In the first story, negative memories were highlighted, in many cases due to a traditional approach to the subject based on the ideology of performance. On the other hand, having offered an alternative approach in the subject of the degree in which the educational value of PE is justified, it can be seen a very positive change in the sense and the justification of including this subject in the curriculum of primary education.
\end{abstract}

Keywords: Assessment; autobiographical tale; physical education; higher education

\title{
Resumo
}

Neste trabalho utilizamos relato autobiográfico como um elemento de avaliação. Ele pediu aos alunos para elaborar duas contas, uma com memórias de aulas de educação física (EF) antes de ter concluído os seus estudos no ensino e outra que ofereceu sua visão de EF depois de ter estudado a didática sujeitas EF no ensino primário. Na primeira história, que destacou as memórias negativas, em muitos casos devido a uma abordagem tradicional para o assunto baseado na ideologia do desempenho. Em vez disso, depois de ter dado uma abordagem alternativa para a questão da extensão em que o valor educativo da EF é justificada, observou-se nas histórias uma mudança positiva sobre o significado ea razão para incluir este assunto no currículo Educação primária. Palavras-chave: Avaliação; relato autobiográfico; Educação Física; ensino superior

\section{Introducción}

Las personas somos seres eminentemente narrativos (Frank, 1995). Nuestra forma natural de comprender es contar historias. Mediante la narración, expresamos nuestras experiencias de acuerdo al menú de narrativas que proporciona la cultura en la que estamos inmersos. En ese sentido, parece que las experiencias vividas en las clases de Educación Física (EF) no solamente suelen ser ampliamente recordadas por el alumnado, sino que determinan su relación presente y futura con la actividad física y el deporte (Green et al., 2005). 
Los documentos escritos tales como los cuadernos de notas, diarios reflexivos o memorias, pueden considerarse un buen elemento de evaluación en tanto que permiten obtener información valiosa de los procesos de enseñanza-aprendizaje (Hamodi, LópezPastor \& López, 2015). Además, esta información no sólo resulta útil en el contexto en el que se desarrolla, sino que puede ser incluso transferible a otros contextos similares, dado que aunque las historias son individuales, el contenido arroja información del contexto social y cultural en el que suceden, por lo que las narraciones individuales son al mismo tiempo personales y sociales (Murray, 1999).

El objetivo principal de este trabajo es mostrar una experiencia de uso del relato autobiográfico como elemento de evaluación diagnóstica, que permita además explorar los cambios en la percepción del alumnado sobre la EF después de haber cursado la asignatura de didáctica de la EF en EP.

\section{Contextualización}

La experiencia se ha realizado en el curso 2016/17 con las alumnas y alumnos de segundo curso del grado en magisterio en educación primaria de la Universitat de València. Concretamente, se contó con la participación de 96 estudiantes (76 chicas y 20 chicos) provenientes de dos de los grupos de la asignatura, cuya carga lectiva es de 60 horas presenciales (6 créditos).

\section{Diseño y desarrollo}

Al inicio del curso se solicitó la realización de un primer relato autobiográfico titulado “La educación física y yo”. Este primer relato debía contener información acerca de los recuerdos que tenían de la asignatura de EF antes de haber iniciado los estudios de magisterio en EP.

Durante el desarrollo de la asignatura se han abordado contenidos que justifican el valor educativo de la EF y que huyen de una concepción tradicional basada en la ideología del rendimiento (Molina \& Beltrán, 2007), tales como la EF inclusiva, la EF para la salud, lógicas de juegos alternativas a la competición (cooperativa, paradójica), haciendo uso de una metodología participativa, integradora, crítica, reforzando el autoconcepto, la autonomía y las relaciones intergrupales.

Justo antes de terminar el curso, se solicitó que entregaran un segundo relato, que en este caso debía incluir información relacionada con la experiencia vivida en la 
asignatura de didáctica de la EF en EP, así como su opinión actual del significado de la EF.

La realización de estas dos tareas se correspondía con un 20\% de la nota final de la asignatura, valorándose tanto la relevancia del contenido de los relatos como la calidad y la corrección de la composición. El 80\% restante se dividía en la participación activa en clase (20\%), el desarrollo de una unidad didáctica grupal tutorizada (30\%) y la prueba final de conocimientos teóricos (30\%).

\section{Evaluación}

Con este trabajo se pretendía en un primer momento conocer las experiencias previas de los estudiantes con la EF, tomando como hipótesis que predominaría el recuerdo de un enfoque clásico basado en el rendimiento y en la gimnasia como disciplina deportiva, con la que algunos estudiantes, particularmente las chicas, habrían tenido experiencias negativas. En cambio, tras haber ofrecido una propuesta de EF inclusiva, a partir de una metodología participativa, se deseaba conocer a través de los relatos el efecto transformador o no que podría haber supuesto cursar esta asignatura.

En términos de evaluación, el primer relato se relacionaría con la fase de evaluación diagnóstica inicial. Los siguientes extractos sirven de ejemplo de algunas de las confesiones de los estudiantes, en la que muestran algunas razones por las que predominaron los recuerdos negativos de la asignatura de EF.

Mi experiencia con la EF ha sido bastante decepcionante años atrás. Esa mala experiencia hace que no tenga buenas expectativas con la asignatura. (Alumna)

Nuestra relación [con la EF] era muy buena hasta que con el paso de un nivel educativo a otro, cambió radicalmente. (Alumna)

A pesar que siempre me ha gustado el deporte, nunca me he llevado especialmente bien con la EF. Para mí, siempre fue una dificultad cumplir con los requisitos físicos exigidos. (Alumno)

En cambio, en el segundo relato que se relacionaría con la fase de evaluación cualitativa de la experiencia didáctica, parece que el enfoque de la asignatura les ha aportado en general una visión diferente de la EF. Los siguientes extractos de los relatos permiten mostrar cómo se ha logrado cambiar la opinión acerca de las clases de EF, 
hasta el punto de que algunos estudiantes destacaran la asignatura como una de las mejores que habían cursado.

Tengo que admitir que mi opinión ha cambiado más de lo que me esperaba.

Me gustaría que las personas que piensan como yo, cursaran esta asignatura. (Alumna)

Puedo decir que esta asignatura ha superado, y con creces, mis expectativas. Tengo que confesar que me planteé coger la especialidad de Educación Física, a pesar de que tenía pensado hacer otra especialidad. (Alumno)

Me gustaría destacar la clase en la que se habló del miedo a enfrentarse a esta asignatura. Nos hizo reflexionar y empatizar con estas personas. (Alumna)

\section{Conclusiones}

A partir de la experiencia pedagógica descrita, se puede concluir que la elaboración de relatos autobiográficos ha resultado ser un buen elemento de evaluación, tanto diagnóstica como procesual, dado que han permitido mostrar cómo el alumnado ha comprendido el verdadero significado y justificación de la EF en el ámbito de la EP. Además, a la luz de los comentarios satisfactorios recibidos en el segundo relato en referencia a la asignatura, consideramos que se ha logrado transformar la visión clásica y peyorativa de la EF que normalmente posee el alumnado antes de cursar los actuales estudios de magisterio.

\section{Referencias}

Frank, A. (1995). The wounded storyteller. Nuevo York: Sage.

Green, K., Smith, A., \& Roberts, K. (2005). Young people and lifelong participation in physical education: a sociological perspective on contemporary physical education programmes in England and Wales. Leisure Studies, 24, 27-43.

Hamodi, C., López-Pastor, V.M., \& López, A.T. (2015). Medios, técnicas e instrumentos de evaluación formativa y compartida del aprendizaje en educación superior. Perfiles Educativos, 147(37), 146-161. 
Molina, J. P., \& Beltrán, V. J. (2007). Incompetencia motriz e ideología del rendimiento en educación física: El caso de un alumno con discapacidad intelectual. European Journal of Human Movement, 19, 157-180.

Murray, M. (1999). The stories nature of health and illness. En M. Murray y K. Chamberlain (Eds), Qualitative health psychology (pp. 47-63). Londres: Sage. 